Special issue of the 3rd International Conference on Computational and Experimental Science and Engineering (ICCESEN 2016)

\title{
Diffusion Kinetics of Binary Ti-Ni Shape Memory Alloys
}

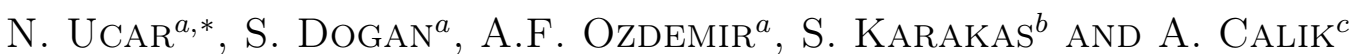 \\ ${ }^{a}$ Physics Department, Art and Science Faculty, Suleyman Demirel University, Isparta, Turkey \\ ${ }^{b}$ Materials Science and Engineering Department, Faculty of Engineering, Cankaya University, Ankara, Turkey \\ ${ }^{c}$ Department of Manufacturing Engineering, Technology Faculty, Suleyman Demirel University, Isparta, Turkey \\ In this work, the boriding of binary $\mathrm{Ti}-\mathrm{Ni}$ shape memory alloys was carried out in a solid medium at 1173 \\ and $1273 \mathrm{~K}$ for 2,4 , and $8 \mathrm{~h}$ using the powder pack method with Ekabor-Ni powders. The boride layer was \\ characterized by optical microscopy and scanning electron microscopy. The obtained results show that boride layer \\ thickness increases with the increasing boriding temperature and time. Depending on temperature and boride layer \\ thickness, the diffusion process is thermally activated, with the mean value of the activation energy being close to \\ $67 \mathrm{~kJ} / \mathrm{mol}$.
}

DOI: 10.12693/APhysPolA.132.524

PACS/topics: boriding, shape memory alloys, microhardness, boride layer, diffusion

\section{Introduction}

Near-equiatomic Ti-Ni alloys are widely used in engineering, aeronautics, dentistry, and medical fields because of their superior shape memory effect and superelasticity [1, 2]. But, Ni-Ti instruments exhibit a lower microhardness (303-362 VHN) compared to stainless steel materials $(522-542 \mathrm{VHN})[3,4]$. When $\mathrm{Ni}-\mathrm{Ti}$ alloys are used as an engineering material, they must have highest corrosion resistance and microhardness. Coating with certain compounds is one way of improving material properties such as hardness, wear performance and corrosion resistance [5, 6]. Tabur et al. [7] showed that the boronised steels exhibit surface hardness values over $2000 \mathrm{HV}$. In addition to this, it has been shown that wear and corrosion behaviour of the steel were improved about 25 and 95 times, respectively, by the boronising treatment compared with the unboronised steels [8].

In boriding process, boron atoms diffuse into the surface of the workpiece to produce hard boride layers without requiring high technology. It has been pointed out that the growth kinetics of hard boride layers are affected by the type of microstructure, boriding temperature, treatment time [9-11]. Therefore, estimating the kinetic parameters of developing boride layers during the boriding process is crucial. In relation to this, it has been shown that the thickness of a boride layer parabolically increases with time [12-14]. In addition, it has been found that the process temperature plays a much more important role in the layer-thickness increase than the treatment duration, as the boride layers formed at $1123 \mathrm{~K}$ show a greater thickness than at $1273 \mathrm{~K}$ [12]. These behavior have been explained with the increased diffusion and accelerated formation of the boride layers.

In the literature, a number of studies have previously been carried out on microstructural characterization and

*corresponding author; e-mail: nazimucar@sdu.edu.tr mechanical properties of shape memory alloys, in both bulk $[15,16]$ and thin film forms [17-19]. However, there has been no report in the past on the boriding behaviour of binary Ni-Ti shape memory alloys. In this paper, the influence of boronizing time, temperature on the thickness and morphology of boride layers obtained on binary Ti-Ni shape memory alloys is analyzed. Also, diffusion activation energy $(Q)$ was calculated by building growth kinetics equation of the whole coating layer.

\section{Experimental method}

Binary $\mathrm{Ti}-\mathrm{Ni}(\mathrm{Ni}-45.6 \% \mathrm{Ti})$ shape memory alloys were cut in the dimension of $2 \times 2 \times 10 \mathrm{~mm}^{3}$. The boronizing of binary Ni-45.6\% Ti shape memory alloys was carried out in a solid medium at $1173 \mathrm{~K}$ and $1273 \mathrm{~K}$ for 2 , 4, 6 , and $8 \mathrm{~h}$ using the powder pack method with Ekabor Ni powders. The samples were heat treated in an electrical resistance. The thickness of borides was measured by means of a digital thickness measuring instrument attached to an optical microscope (Nikon MA100). The boride layer thickness values given in the results section are averages of at least 12 measurements. The presence of borides on the surface of the boronized alloys was determined by using the X-ray diffractometer (Rigaku D-MAX 2200 ) with a $\mathrm{Cu} K_{\alpha}$ radiation of $0.15418 \mathrm{~nm}$ wavelength. Metallographic sections were prepared to observe morphological details by the use of optical microscopy and scanning electron microscopy (SEM JEOL5600LV).

\section{Results and discussion}

The cross-section morphologies of the boronised binary Ti-Ni shape memory alloys are shown in Figs. 1 and 2 . As can be seen in these figures, 3 distinct regions have been identified on the surface of the borided graphite cast iron: (i) the boride layer including borides, (ii) the transition zone, and (iii) the matrix that is not affected by boron. The boride layer exhibited a smooth, columnar morphology (Fig. 1 and 2). Also, it was observed that 
the thickness of the boride layer increases with increasing temperature (Fig. 1) and increasing treatment time (Fig. 2) as indicated in literature [20-23]. The obtained average boride layer thickness of values boronised binary Ti-Ni shape memory alloys were 26, 78, $94 \mu \mathrm{m}$ and 32 , $95,123 \mu \mathrm{m}$ for 2,4 , and $8 \mathrm{~h}$ at 1173 and $1273 \mathrm{~K}$, respectively. As a result, we say that the boride layer thickness increases when the boronizing temperature and increasing treatment time increase due to the diffusion of boron atoms.

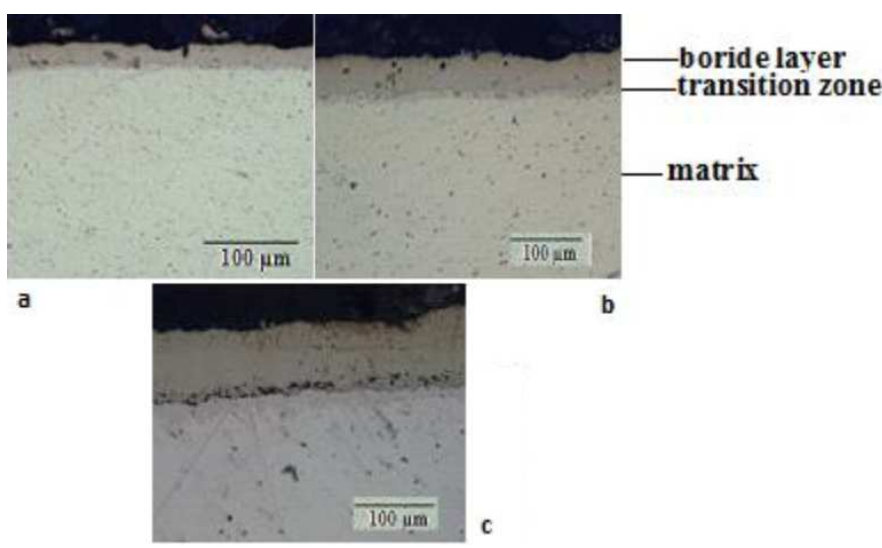

Fig. 1. Cross-sections of the borided binary $\mathrm{Ti}-\mathrm{Ni}$ shape memory alloys: (a) $1173 \mathrm{~K}-2 \mathrm{~h}$, (b) $1173 \mathrm{~K}$ $-4 \mathrm{~h}$ and (c) $1173 \mathrm{~K}-8 \mathrm{~h}$.

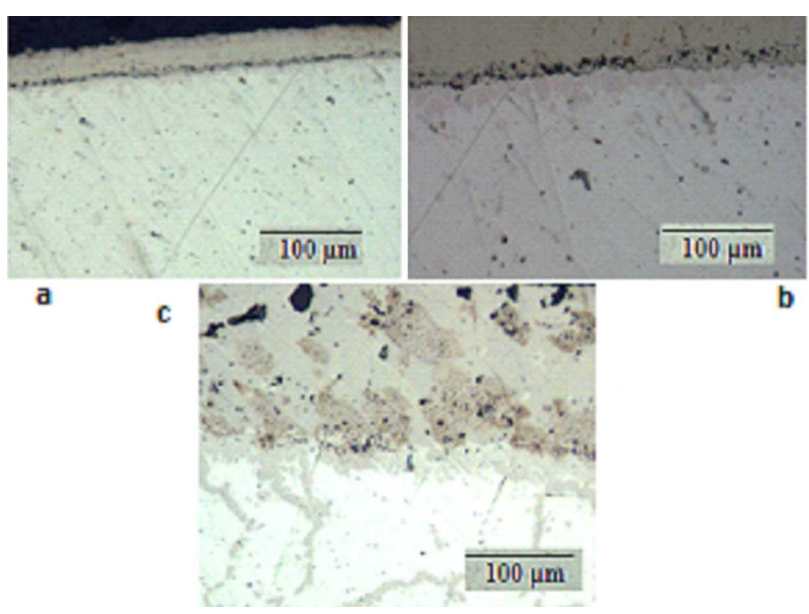

Fig. 2. Cross-sections of the borided binary $\mathrm{Ti}-\mathrm{Ni}$ shape memory alloys: (a) $1273 \mathrm{~K}-2 \mathrm{~h}$, (b) $1273 \mathrm{~K}$ $-4 \mathrm{~h}$ and (c) $1273 \mathrm{~K}-8 \mathrm{~h}$.

Figure 3 shows XRD patterns of the borided Ni-Ti specimens for 2 and $8 \mathrm{~h}$ at $1273 \mathrm{~K}$. Both of the patterns clearly show the presence of $\mathrm{TiB}_{2}$. Other phases detected on the surface of the borided specimens mainly included silicides and borosilicides of nickel [24]. These phases formed due to the additional presence of $\mathrm{SiC}$ in the boriding powders, which is used as a diluent for the boriding source $\left(\mathrm{B}_{4} \mathrm{C}\right)$. These phases were identified as
$\mathrm{Ni}_{2} \mathrm{Si}, \mathrm{NiSi}$, and $\mathrm{Ni}_{4.6} \mathrm{Si}_{2} \mathrm{~B}$. Looking carefully at Fig. 3, we see that NiSi phase is not detected in the borided alloys for $2 \mathrm{~h}$. It is well known that silicidization of nickel often results in the coexistence of nickel silicides $\mathrm{Ni}_{2} \mathrm{Si}, \mathrm{NiSi}$, and $\mathrm{Ni}_{5} \mathrm{Si}_{2}$, and that the presence of boron in addition to silicon can also result in the occurrence of borosilicides such as $\mathrm{Ni}_{4.6} \mathrm{Si}_{2} \mathrm{~B}, \mathrm{Ni}_{4.29} \mathrm{Si}_{2} \mathrm{~B}_{1.43}$, and $\mathrm{Ni}_{6} \mathrm{Si}_{2} \mathrm{~B}$.

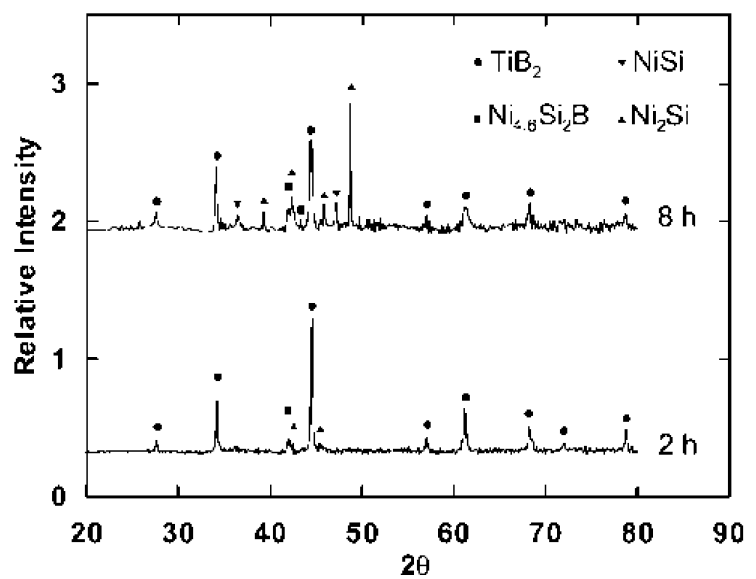

Fig. 3. X-ray diffraction patterns of borided binary Ti-Ni shape memory alloys for 2 and $8 \mathrm{~h}$ at $1273 \mathrm{~K}$.

Now let us consider the activation energy for the boronised binary $\mathrm{Ti}-\mathrm{Ni}$ shape memory alloys. The growth kinetics of the boride layer is controlled by the boron diffusion and the boride layer growing obeys the parabolic law $[12,14,25]$ :

$$
d^{2}=K t
$$

where $d$ is the boride layer thickness $[\mu \mathrm{m}], t$ treatment time [min], and $K$ is boron growth rate constant depending on boronizing temperature. On the other hand, the relationship between the growth rate constant $K$, activation energy $Q$ and temperature can be expressed as an Arrhenius equation

$$
K=K_{0} \exp \left(\frac{Q}{R T}\right) .
$$

Consequently, from the above equation, the activation energy for the boron diffusion in the boride layer is determined by the slope obtained by the plot $\ln K$ versus $1 / T$. Consequently, the activation energy for the boron diffusion in the boride layer is determined by the slope obtained by the plot versus using Eq. (2). In this study, the activation energy for the boron diffusion in the coating layer of the boronised binary $\mathrm{Ti}-\mathrm{Ni}$ shape memory alloys is determined to be $67 \mathrm{~kJ} / \mathrm{mol}$. Corresponding to this, for the same temperatures, the activation energies of AISI 52100, AISI H10 steels, pure Fe and pure Co have been obtained as 269, 160 [26], 90 [27] and 231.7 $\mathrm{kJ} \mathrm{mol}^{-1}[28]$, respectively for pack boriding. Looking at the these results, the activation energy value has been affected by microstructure of sample rather than boronizing temperature and boronizing methods. 


\section{Conclusion}

The results of the current study can be summarized as follows:

- The boride layer exhibited a smooth, columnar morphology, and consisted mainly of $\mathrm{TiB}_{2}$. Traces of $\mathrm{Ni}_{2} \mathrm{Si}, \mathrm{NiSi}$, and $\mathrm{Ni}_{4}{ }_{6} \mathrm{Si}_{2} \mathrm{~B}$ were also detected from XRD patterns.

- The thickness of the boride layer increases with increasing temperature and treatment time due to the diffusion of boron atoms.

- The activation energy for borided binary $\mathrm{Ni}-$ 45.6\% Ti shape memory alloys was $67 \mathrm{~kJ} \mathrm{~mol}^{-1}$, which is much lower than that for many borided steels and pure metals. It is to claim that diffusivity of $\mathrm{B}$ atoms also depends on microstructure and affinity of $\mathrm{B}$ atoms.

\section{Acknowledgments}

This study was supported by the Scientific Research Projects Coordination Unit of Suleyman Demirel University (Project reference no. SDU-BAP 4290-YL1-15).

\section{References}

[1] Y. Sahin, K.E. Oksuz, JOM 66, 61 (2014).

[2] J. Van Humbeeck, 134 Mater. Sci. Eng. A 273-275, (1999).

[3] P. Brockhurst, E. Hsu, Aust. Endod. J. 24, 115 (1998).

[4] P. Brockhurst, I. Denholm, J. Endod. 22, 68 (1996).

[5] E. Atik, Mater. Struct. 31, 418 (1998).

[6] B.S. Mann, Wear 208, 125 (1997).

[7] M. Tabur, M. Izciler, F. Gul, I. Karacan, Wear 266, 1106 (2009).

[8] E. Yilmaz, N. Ucar, A. Calik, S. Karakas, R. Selbas, J. Balkan Tribol. Assoc. 17, 4 (2001).
[9] G. Stergioudis, Cryst. Res. Technol. 41, 1002 (2006).

[10] H. Kemi, C. Sasaki, M. Kitamura, N. Satomi, Y. Ueda, M. Nishikawa, J. Nucl. Mater. 26, 1108 (1999).

[11] I. Ozbek, C. Bindal, Surf. Coat. Technol. 154, 14 (2002).

[12] C. Li, B. Shen, G. Li, C. Yang, Surf. Coat. Technol. 202, 5882 (2008).

[13] P. Feliner, M. Chrenkova, Chem. Papers 46, 226 (1992).

[14] O. Azouani, M. Keddam, A. Brahimi, A. Sehisseh, J. Min. Metall. B-Metall. 51, 49 (2015).

[15] W. Ni, Y.-T. Cheng, D.S. Grummon, Appl. Phys. Lett. 80, 3310 (2002).

[16] K. Gall, K. Juntunen, H.J. Maier, H. Sehitoglu, Y.I. Chumlyakov, Acta Mater. 49, 3205 (2001)

[17] H.D. Espinosa, B.C. Prorok, M.J. Fischer, J. Mech. Phys. Solids 51, 47 (2003).

[18] W. Ni, Y.-T. Cheng, M. Lukitsch, A.M. Weiner, L.C. Lev, D.S. Grummon, Wear 259, 842 (2005).

[19] X.-G. Ma, K. Komvopoulos, Appl. Phys. Lett. 83 3773 (2003).

[20] K. Genel, Vacuum 80, 451 (2006).

[21] M.A. Bejar, E. Moreno, J. Mater. Process. Technol. 173, 352 (2006).

[22] O. Ozdemir, M.A. Omar, M. Usta, S. Zeytin, C. Bindal, A.H. Ucisik, Vacuum 83, 175 (2009).

[23] H. Yang, H. Ning, G. Tang, Y. Li, Y. Zhang, in: 2010 2nd Int. Conf. on Mechanical and Electrical Technology (ICMET 2010)

[24] N. Ucar, N. Turku, A.F. Ozdemir, A. Calik, Acta Phys. Pol. A 130, 492 (2016).

[25] S. Sen, U. Sen, C. Bindal, Vacuum 77, 195 (2004).

[26] Y. Kayali, I. Gunes, S. Ulu, Vacuum 86, 1428 (2012).

[27] P. Asthana, H. Liang, M. Usta, A.H. Ucisik, J. Tribol. 129, 1 (2007).

[28] A. Calik, S. Karakas, N. Ucar, F. Unuvar, Kovove Mater. 52, 1 (2014) 